\title{
OS SILÊNCIOS POÉTICOS DAS PROSAS: ROUSSEAU POR SARTRE
}

\author{
THE POETIC SILENCE OF THE PROSES: Rousseau by Sartre \\ LOS SILENCIOS POETICOS DE LAS PROSAS: Rousseau por el Sartre
}

\author{
Luciano da Silva Façanha \\ Professor Doutor da Universidade Federal do Maranhão (UFMA) \\ lucianosfacanha@hotmail.com
}

\begin{abstract}
RESUMO: Embora Sartre esteja se referindo à figura de vários escritores, e não, especificamente a Rousseau, mas também, a ele, afirma que os poetas são homens que se recusam a utilizar a linguagem, mesmo utilizando-a constantemente. E Maurice Blanchot, ao falar da questão literária e da linguagem, nos diz que estas singularidades na literatura nascem com Rousseau, pois, em um século no qual não há quase ninguém que não seja grande escritor, Rousseau é o primeiro a escrever com tédio, como no momento em que diz: nada me cansa, tanto como escrever, a não ser pensar. Estes homens vivem numa crise da linguagem que eclodiu numa crise poética, provocada, precisamente, por suas atitudes poéticas. Sartre elenca uma série de possíveis fatores históricos, sociais etc., que poderiam ter ocasionado a crise dos escritores em face das palavras, em se servir delas e agir contra ela, e destaca uma célebre observação de Bergson ao perceber que os escritores, ao abordarem sobre a linguagem, dentre eles o genebrino, fazem isto com um sentimento de estranheza extremamente frutífero, dando vazão a uma crescente produção de suas obras. Quanto aos leitores desavisados, acabam adaptando esses escritos, às mais diversas interpretações, e transformando essas obras, a partir de fragmentos e trechos deslocados, numa linguagem completamente engajada, a exemplo dos revolucionários de 1789.
\end{abstract}

PALAVRAS-CHAVE: Literatura. Filosofía. Poesia. Prosa. Linguagem.

ABSTRACT: Although Sartre make reference to the figure of several writers, and not, specifically to Rousseau, but a lot of them, the autor affirm that the poets are men who refuse to use the language, even using it constantly. And Maurice Blanchot to speak about the literary question and of the language, says that singularity in the literature be born with Rousseau, for in a century where there is not almost nobody that is not a big writer, Rousseau is the first to write with boredom, like in the moment that he says: nothing tired me, as much as to write, beyond to think. These men live a crisis of the language that appeared in a poetic crisis, provoked precisely, for your poetic attitude. Sartre enumerate several possible historics factors sociais, etc; that could have occasioned the writer' crisis in front of the words, to use them and act against them and detach one celebrated observation of Bergson to realize the writers that when speak about the language, among them, the genevan, make this with a strange feeling much fructiferous, giving space to a growing production of his work. While the imprudent reader finish adapting that works, from fragment and pieces dislocated, in a language completely engaged, an example of the revolutionary of 1789 , like is the case of Rousseau.

KEYWORDS: Literature. Philosophy. Poetry. Prose. Language.

RESUMEN: Aun Sartre haga referencia a figuras de varios escritores, y no, específicamente a Rousseau, pero también a él, afirma que los poetas son hombres que se recusan a utilizar el lenguaje, mismo utilizándola constantemente. Y Maurice Blanchot, al hablar de la cuestión literaria y del lenguaje, nos dice que estas singularidades en la literatura nacen con Rousseau, pues, en un siglo en que no hay casi ningún que no sea grande escritor, Rousseau es el primero a escribir con aburrimiento, como en el momento que dice: nada me fatiga tanto como escribir, a no ser piensar. Estos hombres viven en una crisis del lenguaje que surgió en una crisis poética, causada, exactamente, por sus actitudes poéticas. Sartre enumera una serie de posibles factores históricos, sociales etc.; que podrían tener ocasionado la crisis de los escritores en face de las palabras, al servirse de ellas y actuar contra ellas, y destaca una célebre observación de Bergson al percibir los escritores que, al abordaren sobre el lenguaje, entre ellos, el ginebrino, hacen esto con un sentimiento de extrañeza extremamente prometedor, dando posibilidad a una creciente producción de sus obras. Cuanto a los lectores desavisados, acaban adaptando eses escritos, a las más diversas interpretaciones, y transformando esas obras a partir de fragmentos y trechos desarticulados, en un lenguaje completamente enrolado, a ejemplo de los revolucionarios d 1789.

PALABRAS CLAVE: Literatura. Filosofía. Poesía. Prosa. Lenguaje.

Artigo recebido em setembro de 2015

Aprovado em novembro de 2015

Cad. Pes., São Luís, v. 22, n. Especial, set./dez. 2015 


\section{1 | INTRODUÇÃO}

É muito oportuna a observação que Jean-Paul Sartre faz no seu livro Qu'est-ce que la littérature? (Que é a literatura?). No primeiro capítulo, "Que é escrever?", ao responder à acusação da crítica de "detestar a poesia" pelo fato de não publicar nada desse teor: poesias, contos, poemas em Les Temps Modernes, defende-se não só mencionando sua vasta produção contemporânea em outras publicações, mas ratifica o fato de não querer tornar a poética uma escrita engajada, pois, mesmo ela se servindo também da palavra, como a prosa, não é feita da mesma forma; "na verdade, a poesia não se serve de palavras", avisa Sartre (2004, p. 12), "ela as serve". Ora, a linguagem utilizada pelo Bárbaro Rousseau em suas obras, mesmo tratando de coisas como a crítica ao progresso, é a palavra que serve a obra, é um modo diferente, além de muitos outros exemplos como a alegoria da Prosopopeia de Fabrício no Discurso sobre as ciências e as artes, o mitologema do Deus Glauco no Discurso sobre a origem e os fundamentos da desigualdade entre os homens, o próprio Estado de Natureza enquanto referencial ficcional para se pensar na oposição ao estado de civilização em que nos encontramos. Conforme Sartre (2004, p. 12), "o poeta se afastou por completo da linguagem-instrumento; escolheu de uma vez por todas a atitude poética que considera as palavras como coisas e não como signos".

Embora Sartre (2004) esteja se referindo às figuras de vários escritores, e não, especificamente a Rousseau, mas também a ele, afirma que "os poetas são homens que se recusam a utilizar a linguagem" (SARTRE, 2004, p. 12), mesmo utilizando-a constantemente. E Maurice Blanchot, ao falar da questão literária e da linguagem, nos diz que "estas singularidades na literatura nascem com o Rousseau", pois, num século em que não há quase ninguém que não seja grande escritor, Rousseau é o primeiro a escrever com tédio, como no momento em que relata: "nada me cansa, tanto como escrever, a não ser pensar". Estes homens vivem numa crise da linguagem que eclodiu numa crise poética, provocada, precisamente, por suas "atitudes poéticas".

Sartre (2004, p. 16) elenca uma série de possíveis fatores históricos, sociais etc., que poderiam ter ocasionado a crise dos escritores em face das palavras, em se servir delas e agir contra ela, e destaca uma célebre observação de Henri Bergson ao perceber que os escritores, ao debaterem sobre a linguagem, dentre eles o genebrino, isto surge "com um sentimento de estranheza extremamente frutífero"1, dando vazão a uma crescente produção de suas obras. Quanto aos leitores desavisados, acabam adaptando esses escritos às mais diversas interpretações, e transformando essas obras, a partir de fragmentos e trechos deslocados, numa linguagem completamente engajada, a exemplo dos revolucionários de 1789. Claro que esse talvez seja o futuro de toda obra e de todo grande autor, os leitores se apoderando da forma como bem entendem, o que provavelmente poderia ser o que se está fazendo nesse momento, se não houvesse um comprometimento com o entendimento do que seja o próprio ato de escrever e o modo como Rousseau

\footnotetext{
1 Destaca-se que Salinas Fortes, grande leitor e admirador de Sartre, também fez questão de mencionar no seu livro introdutório ao pensamento de Rousseau, O bom selvagem, a interessante observação que o filósofo Henri Bergson fez em texto datado de 1912 a respeito de Rousseau, como sendo, 'por excelência, o autor sobre o qual todo mundo se julga apto a discutir, sem se dar ao trabalho de ler de fato sua obra'; sem se dar conta de que a obra é complexa, dessa maneira, acabam se equivocando por estratégias e recursos de um autor que faz da escrita uma arte, portanto, em qualquer circunstância, escrever sobre esse autor é algo de grande responsabilidade. Cândido (1988, p. XIII), nos comentários do livro póstumo Retrato Calado do Salinas Fortes, observou que o "eixo central" da reflexão do Salinas "se encontrava no entrecruzamento de Rousseau e Sartre", mesmo não sendo algo revelado, mas implícito. Talvez por isso a nossa insistência de tornar visíveis essas linhas. Também, não por acaso diríamos que há um entrecruzamento entre Salinas e Sartre, onde se encontra uma reflexão sobre Rousseau. Porém, da mesma forma considerada por Cândido (1988, p. XI-XIII), "não mais a utopia do heroísmo revolucionário, mas o indivíduo precário, exposto e vulnerável".
} 
escreve; pois, Sartre adverte que, se assim fosse, seria perfeitamente compreendido falar de um "engajamento poético", ou, como se intitulou nesse artigo: Os silêncios poéticos das prosas: Rousseau por Sartre, sem buscar seus sentidos nem sempre imaginados. Mas é evidente que "a emoção, a própria paixão", continua Sartre (2004, p. 17), "e por que não a indignação social" -, estão na origem de um escrito poético; porém, segundo o autor, "não se exprimem nele, como num panfleto ou numa confissão" (SARTRE, 2004, p. 17). Por isso, numa prosa, quando os sentimentos são expostos, o autor acaba esclarecendo, pela própria necessidade da clareza da linguagem; já, no caso da poética, quando o escritor extravasa suas paixões, deixa de reconhecê-las, pois,

as palavras se apoderam delas, ficam impregnadas por elas e as metamorfoseiam; não as significam, mesmo aos seus olhos. A emoção se tornou coisa, passou a ter a opacidade das coisas; é turvada pelas propriedades ambíguas dos vocábulos em que foi confinada. (SARTRE, 2004, p. 17).

É o êxtase das palavras, como diz Sartre (2004, p. 18), da "frase-coisa", inesgotáveis como coisas, pois "extravasam por toda parte o sentimento que as suscitou".

\section{2 | DESENVOLVIMENTO}

A partir dessa fundamentação de Sartre (2004, p. 18), como esperar algum tipo de poética tribunícia de Jean-Jacques Rousseau? "Como esperar que o poeta provoque a indignação ou o entusiasmo político do leitor quando, precisamente, ele o retira da condição humana" e convida o leitor a "considerar, com os olhos de Deus, o avesso da linguagem?" Como esperar que os outros também sintam um mal estar na civilização? De indignação, de perceber que alguma coisa vai mal e que o curso da história poderia ser diferente?

Se poética não tem a ver com engajamento e, prosa sim, é bom lembrar que tanto o prosador quanto o poeta lidam com a escrita, embora pareçam universos incomunicáveis, pelo enquadramento do que vale para cada um. Conforme Sartre (2004, p. 32) observa em nota:

\footnotetext{
É claro que em toda poesia está presente uma certa forma de prosa, isto é, de êxito; e reciprocamente, a prosa mais seca encerra sempre um pouco de poesia, isto é, certa forma de fracasso: nenhum prosador, mesmo o mais lúcido, entende plenamente o que quer dizer; ou diz demais, ou não diz o suficiente, cada frase é um desafio, um risco assumido; quanto mais se vacila, mas a palavra se singulariza; ninguém como mostrou Valéry, consegue compreender uma palavra até o fundo. Assim, cada palavra é empregada simultaneamente por seu sentido claro social e por certas ressonâncias obscuras; eu quase diria: por sua fisionomia. É exatamente a isso que também o leitor é sensível. E já não estamos mais no plano da comunicação concentrada, mas no da graça e do acaso.
}

Ora, não parece que Rousseau esteja se valendo completamente de uma prosa utilitária, ou melhor, de uma linguagem utilitária, mesmo se servindo das palavras em muitos momentos, e, exatamente por isso, há uma arte sobre os discursos em que não se trata somente de saber se agradam ou desagradam por si próprias, mas, se indicam algo. Ora, mas isso, também, não é uma atitude poética? Ademais, essa atitude na escrita é "linguagem", muitas vezes incompreendida, tida como a linguagem de um bárbaro.

Conforme Sartre (2004, p. 19) observa, esta linguagem se torna "um prolongamento dos nossos sentidos"; são sentimentos espontâneos, pois, "estamos na linguagem como em nosso corpo", que ultrapassamos em muitas outras direções e outros fins, "tal como sentimos as nossas 
mãos e os nossos pés; percebemos a linguagem quando é o outro que a emprega, assim como percebemos os membros alheios". Isso se dá no âmbito das atividades entre as pessoas, de uma sobre as outras.

É interessante se perceber, por exemplo, que em alguns discursos filosóficos, há um silêncio filosófico (como uma afasia), onde não há palavras exatas para explicar alguma coisa, sobretudo para descrever ou designar algo, faltando um juízo organizado, resultando muitas vezes numa linguagem hesitante e fragmentária, mas isso não prejudica a marcha da escrita e sua leitura. "Os silêncios da prosa são poéticos porque marcam seus limites" (SARTRE, 2004, p. 32). Nesse sentido, seria uma incapacidade de usar apropriadamente a linguagem, mesmo havendo seu reconhecimento; Sartre (2004) explica que essa fina e aparente destruição da linguagem é apenas o desmoronamento de uma de suas estruturas, o que assinalaria senão uma contemplação, pelo menos, o seu despertar pelo que falta.

Mesmo quando tudo parece indicar que a prosa não é uma linguagem privilegiada, pois, só à poética cabe a pura contemplação das palavras de maneira desinteressada. É então que Sartre (2004) questiona o fato de que se somente à poética cabe tais encantamentos, qual seria a finalidade do prosador escrever, mais precisamente, do filósofo escrever? Nesse empreendimento, que resolveu investir, por que necessita do recurso à escrita? Qual a insistência? Afinal, já que "a intuição é silêncio e a finalidade da linguagem é comunicar", nos diz Sartre (2004, p. 19), como explicar os momentos do texto de Rousseau em que se observa o mais puro silêncio? Silêncio filosófico? Talvez, porém, esse silêncio poderia se converter numa intuição. Ora, poética também é linguagem, silêncio também é a mais pura linguagem intuitiva do outro. "Deixemos a outros o cuidado de instruir os povos sobre os seus deveres e limitemo-nos a bem cumprir os nossos; não temos necessidade de saber mais!"; sugere Rousseau (1978, p. 352), no final do seu amaldiçoado Discurso sobre as ciências e as artes, e continua:

Oh! Virtude, ciência sublime das almas simples, serão necessários, então, tanta pena e tanto aparato para conhecer-te? Teus princípios não estão gravados em todos os corações? E não bastará, para aprender tuas leis, voltar-se sobre si mesmo e ouvir a voz da consciência no silêncio das paixões?

Ora, isso é intuição, despreocupação com clareza, "saibamos contentarmo-nos com ela e, sem invejar a glória desses homens célebres que se imortalizaram na República das Letras”, nos diz Rousseau (1978, p. 352). Mas, poder-se-ia pensar que essa "estranha" sugestão de intuição seria uma "estranha decisão", porém, Rousseau (1978, p. 352) logo explica a escolha que há entre os letrados, nessa gloriosa distinção: "um sabia dizer bem e o outro bem fazer". O escritor engajado acabou escolhendo um modo de ação, de escrita, onde sua palavra se tornou ação, pois, "abandonou o sonho impossível de fazer uma pintura imparcial da Sociedade e da condição humana [da civilização]" (SARTRE, 2004, p. 20-21). É assim que Rousseau (1978) se revela, seus escritos não têm e nem conseguem manter uma imparcialidade. Ainda com Sartre (2004, p. 20), são escritos "em situação em relação ao homem". Por isso, a escrita de Rousseau (1978, p. 21) é uma atitude poética, pois, se evidencia nos sentimentos: "é no amor, no ódio, na cólera, no medo, na alegria, na indignação, na admiração, na esperança, do desespero que o homem e o mundo se revelam em sua verdade". A partir desses traços, Sartre (2004, p. 21) questiona sobre qual poderia ser o objetivo da literatura, mas, logo percebe: "o escritor decidiu desvendar o mundo e especialmente o homem para os outros homens, a fim de que estes assumam em face do objeto, assim posto a nu, a sua inteira responsabilidade". Isso é ao mesmo tempo um prazer e um entristecer-se, um contentar-se descontente, mas também, um ato de liberdade, pois, a partir desses escritos, não há mais como ignorar o mundo, nem "considerar-se inocente diante dele." É um "engajamento" 
que se dá no "universo da linguagem", em que o filósofo ficou aprisionado na rede da linguagem, como muito bem disse Nietzsche, pois, quem entra nessa cadeia, fica preso de si mesmo, JeanJacques ficou preso de si mesmo, e Sartre (2004, p. 22) adverte:

\begin{abstract}
Não se pode nunca mais fingir que não sabe falar; quem entra no universo dos significados, não consegue mais sair; deixemos as palavras se organizarem em liberdade, e elas formarão frases, e cada frase contém a linguagem toda e remete a todo o universo; o próprio silêncio se define em relação às palavras, assim como a pausa, em música, ganha o seu sentido a partir dos grupos de notas que a circundam. Esse silêncio é um momento da linguagem; calar-se não é ficar mudo, é recusar-se a falar - logo, ainda é falar.
\end{abstract}

Assim, esse deixar passar em silêncio ainda é uma poética tribunícia da reivindicação, pois, sinaliza que algo pode ser pensado, no silêncio das paixões, precisa ser pensado; isso pode, perfeitamente, constituir-se numa reivindicação de Rousseau aos leitores, pois, em todos seus escritos, até mesmo nos Devaneios, em que confessa escrever somente para si mesmo, e nos Diálogos, que julga a si próprio, há essa solicitação, no "recôndito das paixões", pois, falar de si para si, falar de si julgando a si mesmo, não o impedem de escrever, portanto, não deixam de provocar a intuição. Também, é a poética tribunícia de Jean-Jacques, pois, conforme Sartre (2004, p. 22) "ninguém é escritor por haver decidido dizer certas coisas, mas, por haver decidido dizê-las de determinado modo". Isso é o estilo do escritor, o seu específico modo de dizer as coisas, é a sua beleza, que nessa poética "é apenas uma força suave e insensível", que, enquanto numa tela explodiria de imediato, num livro, se esconde, age por persuasão, "acreditamos ceder a argumentos quando na verdade estamos sendo solicitados por um encanto que não se vê".

O prazer estético puro, dos discursos de Rousseau, provindos dos seus sentimentos de indignidade e insatisfação da sociedade do letramento, da poderosa razão, são atitudes poéticas que só vem por acréscimos. É isso que "predispõem as paixões do leitor, sem que este se dê conta"; essa predisposição pode acontecer tanto para o entendimento quanto para a completa repulsa pelo entendimento de muitas das questões que Rousseau nega com tanta veemência; como a ocorrência do progresso da linguagem, a harmonia da música, a instalação do teatro na República de Genebra, a crítica a qualquer representação política, a polidez das artes, a falida educação positiva, a intolerância religiosa, o aperfeiçoamento das ciências e da técnica, se forem pensadas em si mesmas. E com a sua própria escrita, ocorre o mesmo, se o leitor passar a considerá-la "em si mesma", por ela mesma tudo isso perderá completamente o sentido e restará apenas um contraste, que se reverterá na mais plena contradição e na mera excentricidade de um filósofo, que simplesmente pensa no "excessivo engajamento de seus contemporâneos filósofos", que, a partir de um otimismo exagerado do progresso da razão isso contribuiria mais ainda na corrupção do gosto, na degeneração das paixões e na própria decadência do progresso e da civilização; e de forma mais excêntrica, também seria encarado, o fato de Sartre (2004, p. 22) dizer que "o engajamento prejudica a arte de escrever", como premeditação do próprio assassinato da literatura. Porém, todas essas coisas podem ser ditas de diversas formas, por inúmeras expressões artísticas, o conteúdo pode até sugerir o estilo, mas não o comanda; ainda com Sartre (2004, p. 22), "não há temas situados a priori fora da arte literária"; por isso Rousseau alternou suas expressões, realizou verdadeiras variações na tonalidade da sua linguagem para escrever sobre diversas coisas; por circunstâncias, por problemas em aberto, solicitações, expectativas, puro deleite, nesse sentido, Sartre observa que "a arte não perde em nada com o engajamento", muito pelo contrário, são descobrimentos de novas linguagens.

Todas essas obstinações que aparecem nos livros de Rousseau por trás das razões da razão, em que sentimos as razões do coração, seus sentimentos virtuosos, mas também, seus vícios, 
mesmo não convencendo mais em alguns pontos, mas, sua representação das paixões, ainda nos toca e nos comove. Sartre (2004, p. 26-27), então aponta:

\begin{abstract}
Assim, quando um livro apresenta pensamentos inebriantes que oferecem a aparência de razões só para dissolverem sob o nosso olhar e se reduzirem às batidas do coração, quando o ensinamento que se pode extrair dele é radicalmente diferente daquele que o autor quis dar, chama-se a esse livro mensagem. Tanto Rousseau [como tantos outros], nos enviaram mensagens [...].
\end{abstract}

\title{
3 | CONCLUSÃO
}

Portanto, a atitude literária da poética tribunícia de Jean-Jacques ainda é a sua mensagem, "expressão involuntária" dos sentimentos de uma bela alma, indignada com uma sociedade movida por um excessivo progresso racional que, ao negar valores extremamente positivos e universalistas, acaba esquecendo-se do homem. Sartre (2004, p. 27) chama de expressão involuntária por considerar que esses homens de que vem falando, "de Montaigne a Rimbaud, pintaram a si mesmos por inteiro, mas não intencionalmente e como por acréscimo"; mesmo Rousseau, que "fez retoques em suas Confissões" e não abandonou seu lirismo eminentemente romântico mas, que só encontrou a recepção de suas expressões sentimentais no "lirismo demasiado nu dos românticos" -, passou suas mensagens involuntariamente. Desse modo, continua Sartre (2004, p. 27),

já que temos prazer em desarmar as artimanhas de Chateaubriand ou de Rousseau, em surpreendê-los na sua privacidade no mesmo momento em que se fazem de homens públicos, em deslindar as causas particulares de suas afirmações mais universais, pede-se aos recém-chegados que nos proporcionem deliberadamente esse mesmo prazer. Que raciocinem, pois, que afirmem, neguem, refutem e provem; mas a causa que defendem deve ser apenas a finalidade aparente dos seus discursos: a finalidade profunda é entregar-se sem o aparentar.

É fingir de fingimento, ou seja, é a mais pura literatura, uma subjetividade que se entrega sob a aparência de pura objetividade. Um discurso que surge aparentemente do nada, mas, no entanto, equivale ao silêncio, "um pensamento que se contesta a si mesmo, uma Razão que é apenas a máscara da loucura, um Eterno que dá a entender que é apenas um momento de História" (SARTRE, 2004, p. 28).

Chama-se a tudo isso arte literária e fornece aos leitores a oportunidade de consagrar à cultura da subjetividade, utilizando-as sem perigo, pois, "quem levará a sério o humanismo de Rousseau, sabendo que 'Jean-Jacques' colocou seus filhos num orfanato?", questiona Sartre (2004, p. 28), mas quando as "contradições" internas e aparentes entre vida e obra se tornarem nulas, quando a mensagem, em sua profundidade incompreensível, nos tiver ensinado verdades supremas como "o homem não é bom nem mau", então, será alcançado o objetivo principal, o leitor, que poderá finalmente perceber: "Tudo isso não passa de literatura" (SARTRE, 2004, p. 29). E graças à noção de mensagem, que Sartre afirma ser uma alma feita objeto, somente encontrada na intuição do silêncio das paixões ao encerrar um livro... Exatamente como fez Rousseau (1978, p. 352) no seu Discurso sobre as ciências e as artes: "e não bastará, para aprender tuas leis, voltar-se sobre si mesmo e ouvir a voz da consciência no silêncio das paixões? Ai está a verdadeira filosofia". 
OS SILÊNCIOS POÉTICOS DAS PROSAS | Luciano da Silva Façanha

\section{Referências}

CANDIDO, Antonio. Prefácio. In: FORTES, Luís

Roberto Salinas. Retrato Calado. São Paulo: Marco

Zero, 1988.

ROUSSEAU, Jean-Jacques. Discurso sobre as ciências e as artes. Tradução Lourdes Santos Machado. Introdução e notas de Paul Arbousse-Bastide e Lourival Gomes Machado. Consultoria de Marilena Chauí. 2. ed. São Paulo: Abril Cultural, 1978. (Os pensadores).

SARTRE, Jean-Paul. Que é a literatura? Tradução Carlos Felipe Moisés. São Paulo: Ática, 2004. 